\title{
Modeling Myths: \\ On the Need for Dynamic Realism in DICE and other Equilibrium Models of Global Climate Mitigation
}

\author{
Michael Grubb ${ }^{\dagger}$ and Claudia Wieners ${ }^{\ddagger}$
}

\author{
Working Paper No. 112
}

January 25, 2020

\begin{abstract}
We analyze and critique how optimizing Integrated Assessment Models, and specifically the widely-used DICE model, represent abatement costs. Many such models assume temporal independence -abatement costs in one period are not affected by prior abatement. We contrast this with three dimensions of dynamic realism in emitting systems: inertia, induced innovation, and path dependence.
\end{abstract}

We extend the DICE model with a stylized representation of such dynamic factors. By adding a transitional cost component, we characterize the resulting system in terms of its capacity to adapt in path-dependent ways, and the transitional costs of accelerating abatement. We formalize a resulting metric of the pliability of the system, and the characteristic timescales of adjustment.

With the resulting DICE-PACE model, we show that in a system with high pliability, the optimal strategy involves much higher initial investment in abatement, sustained at roughly constant levels for some decades, which generates an approximately linear abatement path and emissions declining steadily to zero. This contrasts sharply with the traditional formulation. Characteristic transition timescales of 20-40 years result in an optimum path

\footnotetext{
$\dagger$ Professor of Energy and Climate Change, University College London.m.grubb@ucl.ac.uk

* Postdoctoral researcher at the Institute of Economics, Scuola Superiore Sant'Anna, Pisa, Italy. c.wieners@santannapisa.it
} 
which stabilizes global temperatures around a degree below the traditional DICE behavior; with otherwise modest assumptions, a pliable system can generate optimal scenarios within the goals of the Paris Agreement, with far lower long run combined costs of abatement and climate damages.

We conclude that representing dynamic realism in such models is as important as - and far more empirically tractable than - continued debate about the monetization of climate damages and 'social cost of carbon'.

https://doi.org/10.36687/inetwp106

\section{JEL Codes: Q5, H23, Q54, Q55}

Keywords: climate change, Integrated Assessment Models, DICE, path dependence, Pliable Abatement Cost Mechanisms.

\section{Acknowledgements}

The paper is an expanded version of a paper submitted to Wiley Interdisciplinary Reviews, and currently in review with that journal.

The research was supported by INET under Grant ID \#INO19-00004, with additional support for the DICE modeling work by ClimateWorks, Grant 19-1466 


\section{Introduction}

Faced with the realities of climate change, the natural instinct of economists, especially, is to estimate the cost of climate change impacts, so as to compare the cost of cutting emissions against the benefits of avoided impacts. This accounts for the huge popularity amongst economists of the DICE model, developed by William Nordhaus, and a much wider family of 'Integrated Assessment Models'.

Most of the DICE-related literature focuses upon the estimation of global damages, often critically. A recent review (Pezzey, 2019) suggests this may be a futile task, in the sense that there may be no objective, globally acceptable answer given profound challenges in estimation including uncertainty, risk, equity and aggregation over space and time. That surely will not stop the effort.

It may however suggest that putting more attention to the apparently simpler task of estimating the cost of abatement may be more productive and practically useful - if done correctly. This article examines how emissions abatement is represented in DICE and, indeed, a far wider set of what are generally known as optimizing equilibrium models. These include models which focus on the least-cost pathway for greenhouse gas emitting sectors, with more sectoral and technological detail (e.g. in energy), but still use equilibrium-related approaches to optimize the global pathway. Such models have generally become known as 'integrated assessment models' (IAMs) because they attempt to integrate large-scale processes at the global level.

For simplicity in this article we use the term optimizing IAMs to describe the class of models which seek to calculate optimal (= least cost) emission pathways, based on input assumptions about the cost of future emission reductions. Since the focus is upon the structure of mitigation costs, many of the points also apply to models which do not include climate damages with an explicit cost-benefit approach (as with DICE), but focus just on equilibrium (global or partial) approaches to analysing abatement costs of a given emissions or concentration target.

The list of such models has become almost endless. This article critiques how their representation of abatement costs affects the optimal global trajectories and the associated economic impacts of emission reductions, with particular reference to DICE as the 'archetypal' such model. DICE seems to dominate the teaching of climate economics in mainstream economics classes, and in contrast to the more detailed partial models, its relatively simple abatement cost structure enables fundamental issues to be more easily articulated.

\section{The Other Denial? Dynamic realism and its omission from equilibrium models}

The aim of the DICE model, and many others following its general philosophy, is to calculate a longterm balance of costs and benefits. Figure 1 shows the results obtained from the most recent version of DICE (2016). With Nordhaus' standard default published assumptions, it produces an emissions path which (after a drop to a present 'optimal level') has modest initial emissions abatement, strengthening over time due to rising climate damages and assumed falling cost of emission abatement. Abatement tends to be deferred, global emissions in 2050 rise back to about present levels before declining at an accelerating rate towards zero early in the next century. The underlying assumptions mean that "climate damages' - represented as impact on global GDP - remain below 4\% of GDP to the end of the century (then doubling by about 2150). Global GDP is assumed to increase seven-fold over the century and climate in the standard DICE is assumed to be a modest issue, with both the global damages and abatement costs having negligible impact on the assumed continued growth in global GDP. 
(a) Emissions, GtCO2

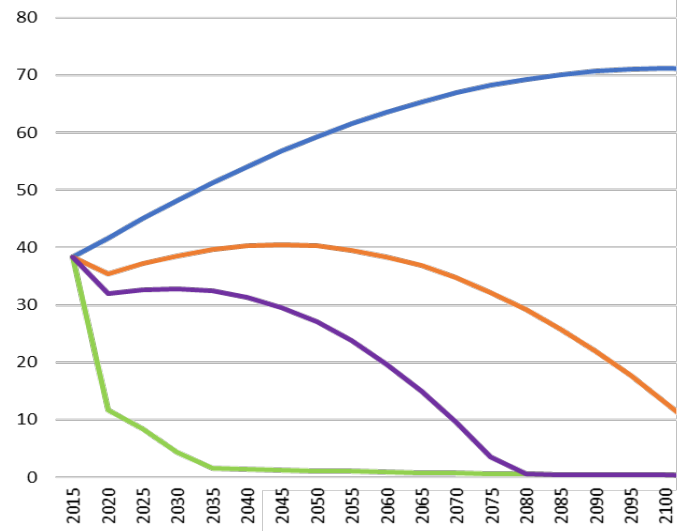

(b) Damage, fraction of GDP(\%)

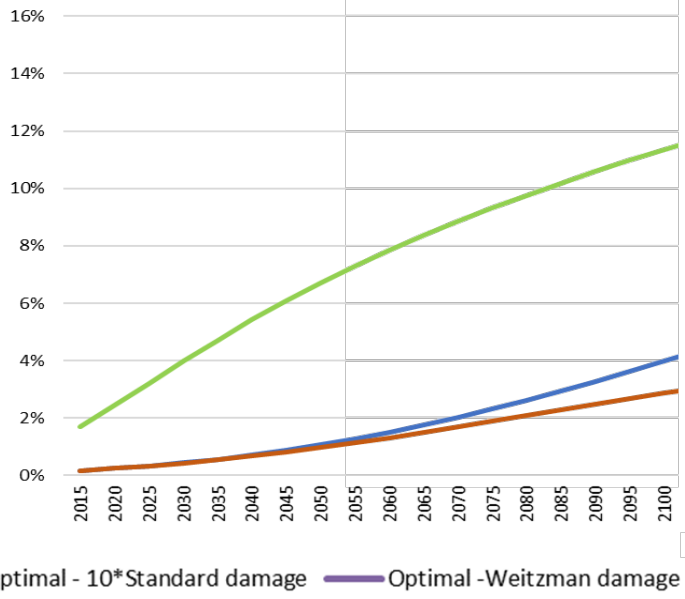

Figure 1: Emissions, temperature and damages from DICE2016 with various damage assumptions

Source: Plots by Pu Yang, UCL, using DICE2016 and its standard assumptions

Such results have been widely criticized, but mainly for the assumed structure and values of climate damages. The chart shows two alternate assumptions. The Weitzman (2011) representation involves damages rising much more sharply above about 2.5 deg.C; in the 'optimum', this is almost exactly offset by greater abatement (the damage lines overlap), since the model assumes perfect foresight into damages well into the next Century. A case with the standard damages increased 10-fold results in precipitous emission reductions, dropping by a factor of 4 in the first model time-step and quickly then to zero, but the assumed inertia in the climate system means that substantially higher damages still accumulate over the century. In this case, the global economy still grows hugely - but with (marginal) climate damages assumed to be bigger than the value of the energy system in the global economy, the model effectively 'deletes' the energy system within a few years.

A huge economic literature has grown criticizing and debating the climate damage assumptions, for which as Pezzey (2019)'s review notes - echoing Weitzman's 'dismal theorem' (Weitzman 2009) there may never be resolution on any timescale quick enough to avert the risk of disaster.

In sharp contrast, hardly any attention has been given to the way in which DICE and other IAMs represent emissions abatement, which is the focus of this paper. Most models represent abatement as incurring an economic cost defined by the degree of emission reduction relative to a 'Business as Usual' projections, taken as the reference trajectory. In its most general form:

Cost at time $t$ of reducing emissions at time $t$ by $\mu, \overline{\mathbf{C}}(\mathrm{t})=\mathrm{f}(\mu(\mathrm{t}))$

Where $\mathrm{f}(\mu(\mathrm{t}))$ can be any general cost function that is monotonically rising (i.e. the bigger the cutback at time $t$, the higher the cost). 
More specifically in DICE, the abatement cost is "a reduced-form type model in which the costs of emissions reductions are a function of the emissions reduction, $\mu(t)$ "1 (Nordhaus \& Sztorc, 2013, eq.6):

$$
\begin{array}{r}
\text { Abatement cost at time } t \text { by } \mu, \overline{\mathbf{C}}(\mathrm{t})=\Lambda(\mathrm{t}) \cdot \operatorname{GDP}(\mathrm{t})=\mathrm{c}_{\mathrm{A}}(\mathrm{t}) \cdot \mu(\mathrm{t})^{\theta} \cdot \mathrm{GDP}(\mathrm{t}) \\
\text { Abatement cost as fraction of global GDP }=\Lambda(\mathrm{t})=\mathrm{c}_{\mathrm{A}}(\mathrm{t}) \cdot \mu(\mathrm{t})^{\theta}
\end{array}
$$

This expresses abatement costs (proportional to global economic output) as depending purely on the reduction $\mu(\mathrm{t})$ below the assumed reference projection (i.e. emissions at time $t$ with no abatement), raised to the power $\theta$, and scaled by $\mathrm{c}_{\mathrm{A}}(\mathrm{t})$, which in DICE comprises two components, both of which decline exogenously over time. ${ }^{2}$

The general approach of Eq.1 seems almost taken for granted in much 'integrated assessment' modeling, as does the specific form of Eq.2 by the DICE community.

Yet a moment's reflection reveals something profoundly odd: it has no intrinsic history. The cost of cutting emissions in 2050, for example, has nothing to do with anything that has gone before; and the level of abatement in 2050, in turn, has no bearing on the cost of, say, getting to 'net zero' emissions thereafter. This is transparent in the DICE equation (2): if the world has done next to nothing by 2050, and then finds unequivocally that catastrophe looms, the modeled costs of slashing emissions thereafter will be completely unaffected by the presence - or total absence - of ambitious action beforehand. In this sense, the cost curves in each period are rigid: they cannot be influenced by the previous abatement path and implied scale of investment in the model.

More complex models may represent a whole range of technologies, each with different costs for a given amount of abatement, and inclusion of plant lifetimes and rate constraints can introduce some important caveats, considered later. But the essence remains much the same. Subject to constraints, such models embody, implicitly or explicitly, an assumption that the cost of cutting emissions by a given amount at time $t$ can be represented without any direct reference to anything that happened earlier; and the progress made by time $t$ has no effect on anything thereafter.

This is clearly unrealistic. It takes time, effort and cost to change complex systems and to write-off, retrofit or replace existing capital stock. The cost of cutbacks will depend on the inherited infrastructure, technologies and industries that have been built up over previous years and decades. And the 'reference' trajectory - the assumed baseline from which the required cutback is calculated - will inevitably reflect the history of accumulated assets, infrastructure, industries, institutions and indeed social norms.

These simple observations reflect two core components temporal interdependence: namely inertia, and induced learning. These, combined with other effects. also serve to generate path dependence. These three concepts are interrelated but analytically distinct.

This article summarizes overwhelming empirical evidence on each of them and explores some implications for modeling. It follows that models which have simple, static and unconnected equilibria in each sequential period are clearly, technically, incorrect. In this article we call this the theoretical assumption of 'temporal independence' (which as explained later is not at all a necessary condition of

\footnotetext{
${ }^{1}$ The DICE texts and many others refer to this as the "emissions reduction rate", the term "rate" being somewhat confusing in the context of this article since it actually refers to the reduction in annual emissions (i.e. difference in $\mathrm{CO} 2$ /year relative to the baseline rate of emissions), not the change in emissions reduction over time).

${ }^{2}$ Note: the DICE handbook and model use the terms $\theta_{1}(\mathrm{t})$ and $\theta_{2}$ respectively for $\mathrm{c}_{\mathrm{A}}(\mathrm{t})$ and the exponent ${ }^{\theta}$; somewhat confusingly, $\theta_{1}(\mathrm{t})$ comprises two components, $\mathrm{C}_{0}(\mathrm{t}) \sigma(\mathrm{t})$, where $\mathrm{C}_{0}$ is an exogenous cost factor declining by $0.5 \%$ per year (representing technological improvement), and $\sigma$ the carbon emissions per unit of GDP in the absence of abatement, initially declining with $1.5 \%$ per year.
} 
General Equilibrium theory itself). Models which embody a structural assumption of temporal independence are, therefore, technically modeling a myth.

Before condemning such models (and considering important qualifications), one should recall George Box's observation that 'all models are wrong, but some are useful'. ${ }^{3}$ The issue is not whether the absence of dynamic realism makes such models wrong. The issue is whether the insights derived from them are useful, or conversely, potentially misleading to evaluating climate change policy; whether the myth is a useful one or is dangerously misleading.

This article sets out various ways in which the assumption of temporal independence is clearly incorrect. Yet much of the IAM community - with some notable exceptions - seems to have become so used to the structural assumption of temporal independence that it is barely even acknowledged. Even valiant recent attempts to strip down Integrated Assessment Modeling to core component assumptions, such as van der Ploeg \& Rezai (2019), precisely for the purpose of analytic transparency, apparently take for granted the assumption of temporal independence without acknowledging it. Similarly, Dietz \& Venmans (2019) develop "a physically consistent, yet surprisingly simple, model of climate policy" specifically to focus on questions of timing - but again, focus on the damages and adopt the standard assumption of temporal independence in the emitting systems.

We note some exceptions in discussing some implications later.

Note that an important variant which has received considerable economic attention is including explicit $R \& D$ investment, which is generally modeled to include a time-lag ( $\& \& D$ in one period may reduce the cost in subsequent periods). However, the R\&D is generally assumed to involve expenditure independent of abatement in any given period. Thus it does not change the underlying assumption of temporal independence between abatement in successive periods, which is the focus of this article.

The reluctance to consider dynamic realism or its implications may exist for many reasons, including an (incorrect, as discussed later) assumption that it conflicts with General Equilibrium theory, and the sheer complexity of most attempts so far to build computable optimizing models which embody more credible dynamics. But the lack of enquiry now appears as a blind spot, amounting almost to denialism of the need to consider dynamic realism and its implications.

This article aims to tackle the issue head-on: to focus on the questions of (a) the evidence that temporal independence is an invalid assumption; (b) whether, and if so in what ways, the absence of dynamic realism in DICE and the large family of equilibrium-based IAMs undermines their usefulness and potentially renders them misleading to policy, and finally (c) demonstrates some implications, including for the apparently imponderable challenges of cost-benefit assessments.

The article is structured as follows. The first three main sections present evidence on the three core components of dynamic realism indicated, noting where and how they may imply divergence of results typically derived from equilibrium models. Each is briefly illustrated with reference to both the empirics, and modeling enquiries. In these sections, we also consider main lines of defense to suggest that some of the issues are either already addressed in many IAMs, or are not really relevant, and explain why such responses are inadequate.

We then turn briefly to consider two apparently core foundations of reluctance to incorporate dynamic realism. One concerns a somewhat more philosophical question - a theoretical misconception which may help explain the reception (both positive and negative) accorded to DICE-like modeling approaches. This concerns their relationship to General Equilibrium theory, in the light of a long-

\footnotetext{
${ }^{3}$ Drawing on the collective wisdom of Wikipedia, the published record of this saying is attributed to a 1976 paper by George Box in the Journal of the American Statistical Association, though clearly there were antecedents of a similar flavor; https://en.wikipedia.org/wiki/All_models_are_wrong
} 
standing theoretical debate (the Sonnenschein-Mantel-Debreu results). The other is the apparent practical complexity of alternatives, which may explain why many other modelers from other disciplines often take similar approaches in partial equilibrium studies.

Combining these points, the final section shows that an alternative structure of cost function, still in a highly stylized way, can capture some of these important features of dynamic realism, can be simply inserted into DICE itself, to produce radically different results. It offers a simple, equally reduced-form approach to answer unequivocally the 'Box' challenge. The neglect of dynamic realism in IAMs based on standard equilibrium approaches, and particularly the DICE-like models applied to cost-benefit analysis of climate policy, does not only make them inconsistent with clear empirical evidence. It means they are wrong in ways which may really matter for the policy conclusions drawn.

\section{Inertia and transitional costs}

The fact that change takes time and can be costly is common sense. The simplest form of inertia arises from the lifetime of capital stock, and particularly infrastructure. Power stations may last some decades, whilst roads, buildings and urban forms last even longer. Electricity and rail networks have typically taken 25-50 years for their phases of major growth; transport networks, even longer (Grübler, Nakićenović, \& Victor, 1999).

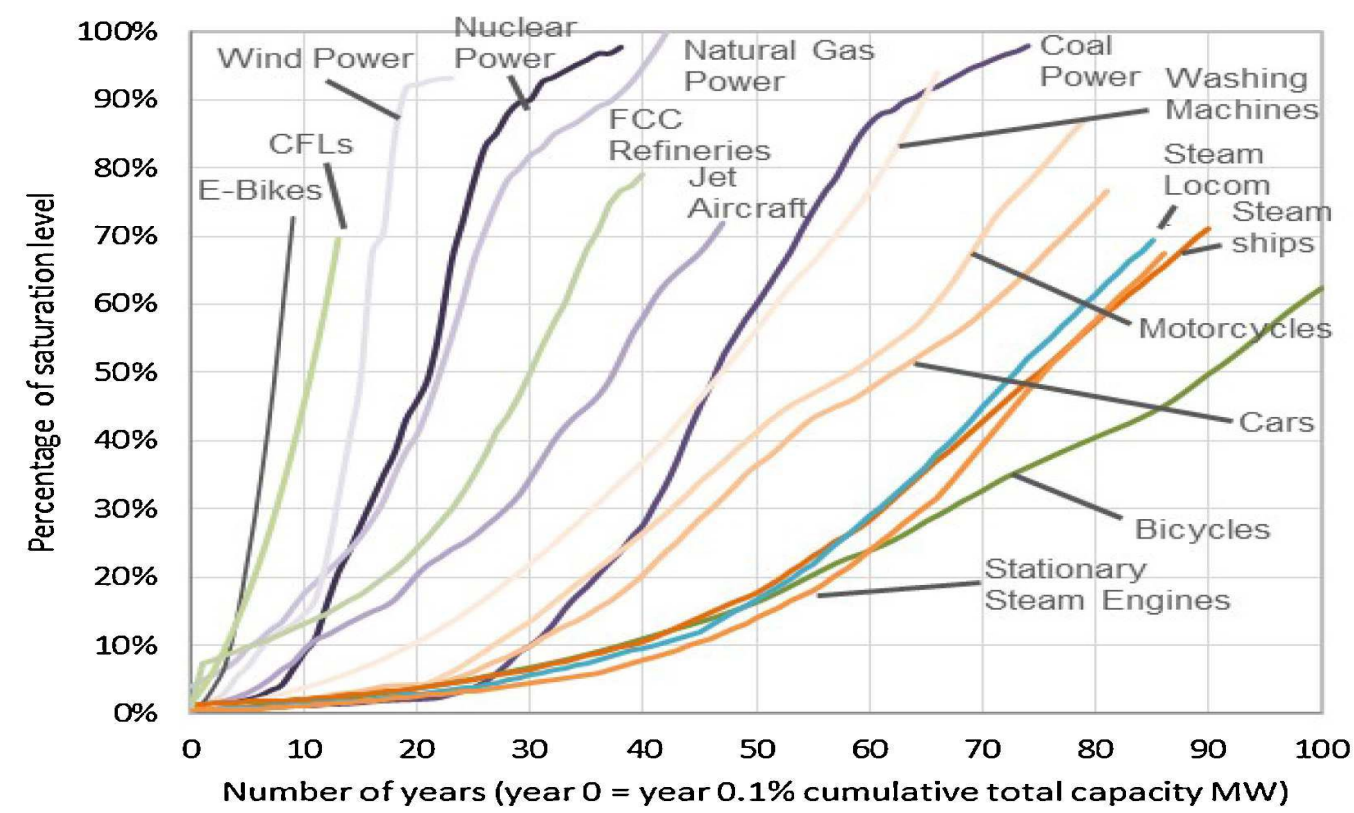

Figure 1 Shape and rate of diffusion of technologies in their initial markets

Source: (Bento \& Wilson, 2016)

Note: The graph shows rising market shares in the initial markets, from the point when each technology passed a threshold of $0.1 \%$ of its eventual maximum installed capacity in that initial (geographic) market. ${ }^{4}$

Other aspects of inertia include network effects which are deeply rooted in the economic systems and supply chains of modern economies, whilst the intertwined nature of technologies and regulatory structures introduces institutional inertia; these combine to constrain rates of growth. Figure 1 shows typical timescales of market penetration in initial markets. In terms of abatement, we are primarily interested in the phase of rapid growth. Nuclear power took about 20 years to go from $10 \%$ to $90 \%$ penetration; coal, about 30 , after a slower formative phase. Consumer goods vary from very fast (e.g.

\footnotetext{
4 "The spatial scale of analysis always corresponds to the initial markets of first commercial application for each technology in which the formative phases marked the emergence of a new innovation system. As examples, wind power is analysed in Denmark, cars in the US, e-bikes in China" (Bento \& Wilson, 2016, p.7)
} 
CFLs), to the much slower adoption of technologies that depended on both consumer wealth and networks (e.g. cars). At the macro level, Bashmakov et al (2019 in review) estimate that even under the impact of the global oil shocks, subsequent energy system adjustments in OECD countries took 25-33 years to work through, and that involved little fundamental changes to fuels outside electricity.

Assuming temporal independence in DICE and similar models with sequential periods just a few years apart is thus inconsistent with the evidence. Of course, transitions can and have occurred more rapidly in particular cases. French nuclear took just ten years to go from $1 \%$ to $25 \%$ of the energy mix. Coal capacity in the UK finally collapsed from 35\% of generation in 2013 to under 5\% of generation just five years later. In India, PV capacity has been almost doubling annually, and its lift-off has seen a dramatic increase from 15 to $500 \mathrm{GW}$ globally within a decade. Nevertheless, global models like DICE which have no inertia clearly omit an important characteristic of global energy systems overall.

\section{A partial defense? The optimal pathway}

There is a simple retort, to argue that this absence of dynamic realism in global optimizing models does not matter because their optimal pathways do not in practice produce cliff-edge behavior (except in the first step, when models such as DICE jump to reflect the global damage of emissions). Indeed, they tend to produce beautifully smooth emission trajectories, with the computed optimal abatement (and implied carbon price) gradually accelerating over time. At first glance, the lack of inertia thus does not in practice seem to be a problem.

Unfortunately, this behavior is generated by the other core assumption in such models: a single global optimization over space and time. The smooth behavior does not reflect inertia at all, but a theoretical abstraction: a least cost pathway that would be adopted by a global decision-maker with full knowledge, perfect foresight, and a single global discount rate, with no myopia or surprises.

Alternatively, one might say they embody innumerable representative agents, all the same, and all perfectly coordinating with perfect foresight over time and space using a common universal discount rate. In terms of realism, this refined description is hardly an improvement.

The resulting profile of abatement has nothing to do with inertia but is a reflection of the assumed discount rate and the benefits of waiting for cheaper technologies to arrive like manna from heaven. Hence the results in Figure 1: if accumulated temperatures may take us over a cliff-edge during the next century (the Weitzman case), everyone knows it now and takes that into account in their investments today. And if we discover tomorrow that climate change is ten times worse than the Nordhaus standard assumption, the model effectively deletes the energy system from the global economy overnight.

One may appeal to Box's dictum, suggesting it may still be useful to produce a theoretically optimum trajectory (along with carbon price and costs) as a reference point. The assumption of global optimality with perfect foresight may make the models more unrealistic, but does it make them less useful?

However, the absence or inadequacy of inertia in such models does carry key 'insight risks'.

One relates to the global pathway in the context of uncertainty. It is commonplace to acknowledge the huge uncertainties and risks around climate change, and to model a wide range of possible outcomes. But uncertainty is a dynamic process (e.g. we appear to be learning at present that ice sheets may be less stable than previously thought and sea levels rise may be correspondingly faster). The politics of action are similarly unstable. Uncertainty (and risks) are not adequately captured by a set of scenarios, each of which assumes that the system has perfect foresight and so smoothly adjusts. This is not the same as modeling the reality that we will only be on one path, that it is likely to prove 'wrong' as knowledge accumulates (even without an inevitable real-world bias towards 'business as usual'). Without inertia, even stochastic studies mislead us with an 'average' pathway which in reality could end up unnecessarily costly. 
This was a central point of modeling of optimal pathways under inertia and uncertainty more than two decades ago (Ha-Duong, Grubb, \& Hourcade, 1997). Higher inertia necessarily implies a more riskaverse pathway - the results emphasized that inertia combined with uncertainty provide clear justification for precautionary action, which is weaker if there is no inertia. Twenty years on, we see the consequences of barely heeding such risks, and face the likely need for rapid transition - which would be clearly cheaper and easier had the world not added another 10 Billion tons to the global stock of CO2-emitting capital in the meantime. After taking account of likely capital retirement over the next 30 years, the default 'optimum' trajectory in DICE (Figure a) would involve constructing a huge amount of new carbon-intensive capital by 2050 - clearly a risky prospect. It is bizarre to suggest this would be an optimum bet.

Another 'invalid insight' risk from models which ignore inertia concerns the prioritization of actions. Such models suggest the classic recommendation of working along the marginal cost curve, starting with the cheapest. In a world of unequal lifetimes between options, this is incorrect, particularly when faced by a serious long-term constraint. By incorporating stock lifetimes in an optimizing model, a seminal contribution by (Vogt-Schilb, Meunier, \& Hallegatte, 2018) demonstrates 'when starting with the most expensive option makes sense' - the need to prioritize action on long-lived assets like transport and buildings infrastructure, even though they may well be more expensive on an initial discounted cost-per-unit basis - a result that can never be obtained from models with temporal independence.

These limitations are somewhat alleviated in more complex and technology-specific models, where individual technologies may be characterized in terms of lifetimes, and new technologies constrained by maximum growth rates. However, these still do not really embody dynamics; they just constrain it. In reality, these are not hard constraints. Carbon-intensive capital can be retired prematurely, and growth rates of clean technologies can be accelerated. Either may incur greater costs. By representing inertia as a constraint, rather than a cost dependent on rates of change, the models still give limited insight into the policy choices that may really matter.

\section{Adding inertia}

In the world of optimizing IAMs, however, there is a much simpler fix available. Inertia simply implies a cost associated with the change in emission pathways. As a basic step, we can just add another term, reflecting inertia, to the DICE framework, with notation such that:

$$
\text { Abatement cost as fraction of GDP, } \mathrm{C}_{\mathrm{AB}}(\mathrm{t})=\mathrm{c}_{\mathrm{A}}(\mathrm{t}) \cdot \mu(\mathrm{t})^{\theta \mathrm{A}}+\mathrm{c}_{\mathrm{B}}(\mathrm{t}) \cdot\left(\frac{d \mu(t)}{d t}\right)^{\theta \mathrm{B}}
$$

We denote this cost $\mathrm{C}_{\mathrm{AB}}(\mathrm{t})$ (which corresponds to the $\Lambda(\mathrm{t})$ in DICE) to emphasize that it is a cost which now includes both standard (A), and transitional (B) cost elements, expressed for simplicity as a fraction of GDP (the total cost $\overline{\mathbf{C}}(\mathrm{t})=\mathrm{C}_{\mathrm{AB}}(\mathrm{t})$. GDP $(\mathrm{t})$ ). This simple addition - adding a transitional ("adjustment") cost which depends on the rate of change of abatement - reflects the first and most obvious dimension of dynamic realism, but offers some surprising implications, which we illustrate later.

\section{Induced learning and cost reduction}

A second and even more important issue concerns innovation. More fundamental than the question of what technology cost projections are made in a model is whether cost reductions are considered to be exogenous - simply, specified externally by the modeling assumptions - or induced by the cumulative impact of policy, investment and market growth within the model. This reflects a long-standing issue in climate economics going back about 25 years, which in turn draws on a much longer heritage of economic theory spanning (Schumpeter, 1934), (Hicks, 1932), (Nordhaus, 1969) himself, (Romer, 1990) and many others. With important exceptions, however, many of many of the IAMs in widespread 
use today, including DICE, continue to treat innovation as exogenous - and many of the exceptions, including 'R\&DICE' (Nordhaus, 2002) have only been applied in experimental or very limited studies.

A major review of innovation modeling (Gillingham, Newell, \& Pizer, 2008a) concluded a decade ago that "our ability to conceptually model technical change has outstripped our ability to validate models empirically." There is however a big difference between uncertainty about specific values, and ignorance about direction - and moreover, evidence about energy-related / low-carbon innovation has further accumulated. The idea that low carbon innovation is influenced by market conditions and relative prices, and by the market scale of low carbon technologies, is not only implicit in the commonsense suggestion of a top economist dating back almost 90 years, it has been supported by many studies since and is empirically unambiguous. The decade since the Gillingham et al review has added further evidence, and insight into the scale.

\section{Evidence on market-induced innovation and induced cost reductions}

Innovation is not a random variable but to a large degree is a product of investment. Some of that investment may be from public R\&D, and/or in other realms (like IT) and hence exogenous, "spilling over" into deployed energy technologies. But much of it is endogenous - within the system, way beyond public R\&D. Innumerable empirical studies have confirmed the original proposition by Hicks (1932) that one would expect the direction of innovation to be influenced by relative prices. Studies in the 1980s already demonstrated that the proportion of private R\&D devoted to energy increased after the 1970s oil price shocks (Lichtenberg, 1986) echoed in numerous studies of patents as reviewed by (Popp, 2002).

Such evidence from decades ago has been enhanced by hundreds of more sophisticated studies. Popp, Newell, \& Jaffe, (2010) reviewed this literature, updated in (Popp, 2019). More than 30 studies document a link between energy prices and patent filing for energy innovations, which is statistically significant to a high level of confidence in around $3 / 4$ of the studies. Overall, the link is so clear that it is becoming commonplace to estimate the elasticity of patents with respect to energy prices, which was typically found to be in the range $0.03-0.06$ (i.e. a 10\% rise in energy prices induced a 3-6\% increase in energy-related patents (Popp (2002); Verdolini \& Galeotti (2011)). In a large study of industrial energy technologies, Ley et al., (2016) find not only that higher energy prices increased patenting (elasticity 0.034$)$, but disproportionately enhance green energy patents $(0.048)$. The impact increases with the lag, reflecting the multi-year timescales of induced innovation.

For low carbon and energy efficient technologies specifically, Kruse \& Wetzel (2016) find an even stronger response (average 0.086, with above 1 for solar PV - as also found by Vincenzi \& Ozabaci (2017)). Lin \& Chen, (2019) estimate that each $1 \%$ increase in electricity price yields almost $1 \%$ long term increase in patents. Aghion, Dechezleprêtre, Hémous, Martin, \& Van Reenen (2016), similarly found an 'patenting elasticity' close to 1 for vehicles, so that a $50 \%$ rise in fuel prices leads to almost $50 \%$ increase in patenting on alternate fueled vehicles.

Not surprisingly, therefore, studies of carbon pricing are also starting to find a positive impact on innovation. Calel \& Deschezlepretre (2016) found that across 3,428 regulated firms the EU emissions trading system increased patents generated for technologies or applications for mitigation or adaptation against climate change by $36.2 \%$ (and $1.9 \%$ for other patent classifications). Many more qualitative studies also trace positive innovation impacts of carbon price and other environmental regulation.

Patents moreover only measure part of innovation process. Concerning renewables, Taghizadeh-Hesary et al (2019) find that energy price rises have had a statistically significant impact in reducing solar module prices in the USA, Japan and China (though not all countries), whilst Kim et al (2017) found carbon pricing to be associated with reduced system costs of wind and solar technologies. In terms of energy efficiency, Knittel (2011) found gasoline prices to have been a principal driver of improved vehicle fuel efficiency, whilst Newell et al (1999) found that electricity and natural gas end-user prices 
induced efficiency improvements in several areas of end-use cost equipment, along with cost reduction in air conditioners.

The key mechanisms of cost reduction, as incentives change and energy technologies are deployed, involve many things beyond patentable innovations. Various forms of learning-by-doing and learningby-using are complemented by simple economies of scale, from unit size to bigger factors and the industry overall, along with the development of global supply chains, and growing confidence which reduces the perceived risks and hence cost of finance.

Engineers often point to 'experience curves' which chart how much the cost of technologies decline with scale (often known as "Wrights law"), typically measured in term of 'learning rates' - the decline of cost associated with a doubling of capacity. Weiss et al (2010, p.411) synthesized studies of fifteen demand-side technologies (largely building heating, lighting and appliances), and found an average, 'learning rate' of $18 \%( \pm 7)$. Rubin et al (2015) reviewed 23 studies of renewables, extended to 45 in a review by Samadi (2018); J. D. Farmer \& Lafond (2016) explore solar PV data in detail in the context of similar relationship identified for 53 technologies. Learning rates vary between technologies and studies, but (with the exception of nuclear power) are uniformly positive: in general technologies get cheaper as their markets grow, and rates have been remarkably high and stable for solar (close to $20 \%$ cost reduction for each doubling of capacity).

The use of learning curves has been criticized for example by (Nordhaus, 2014) because correlation is not causation. However, in addition to the broader evidence above, Bettencourt, Trancik, \& Kaur (2013) had already established that "growing markets have formed a vital complement to public R\&D in driving innovative activity", and one of the most comprehensive subsequent studies (Noailly \& Smeets, 2015), found that higher fossil fuel prices and increased renewable market size had both enhanced renewable innovation. All this is consistent with the evidence from patents. More sophisticated studies disentangle effects of public R\&D from other processes (e.g. private R\&D, learning-by-doing \& using, \& scale); industrial economies-of-scale appear to have been particularly important for PV (Kavlak, McNerney, \& Trancik, 2018) though a key point is the combination of factors which help to build up new technology industries. It is clear that deployment has been a major driver of cost reduction from multiple lines of evidence (Nemet, 2019).

\section{The innovation gap in optimizing equilibrium models}

The cost assumptions of optimizing equilibrium models with cost structure like (Eqs. 1, 2) require projections decades ahead, and we have been running such models for almost 30 years. It is time to fundamentally review the evidence. Probably the single most important determinant of abatement economics is the cost of low carbon energy technologies of potential global significance. Compared to the costs in 2010, the global average price of solar PV had by 2018 fallen by a factor of more than 5 to less than $20 \%$ of the cost a decade earlier (IRENA (2019)). Wind energy costs fell by about $30 \%$, and offshore wind by more than half, as the capacity trebled from $8 \mathrm{GW}$ in 2014 to $23.1 \mathrm{GW}$ in 2018 (GWEC, 2019). Even for offshore wind, auctions in 2019 in northern Europe were close to competitive with fossil fuel generation (BEIS 2019).

Models with exogenous technology assumptions rely on cost projections, so it is relevant to look back at past efforts. Figure 3(a) shows the trend of the observed global average PV life-cycle cost of energy (the green line) compared to various projections. The average global cost of PV is already well below the projections for 2030 made in 2011/12 by a wide range of institutions and built into most models including those reviewed in the IPCC Special Report on Renewable Energy. 
Figure 2: Recent evolution of solar PV energy costs compared to projections and compared to cost of new coal plants.

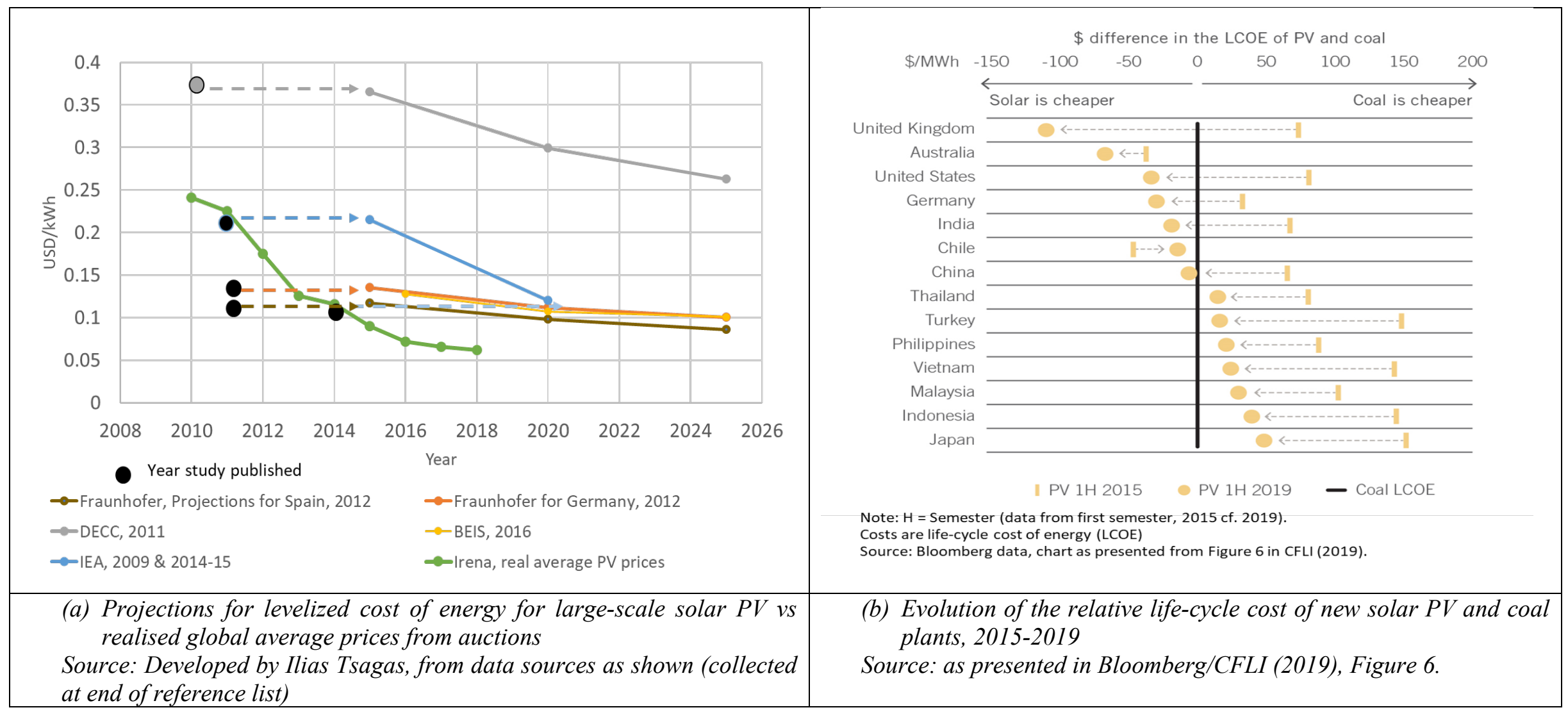


Compared to the cheapest prices now being observed in auctions, the contrast is even more stark. Germany's Fraunhofer Institute projected in 2012 life cycle costs for solar PV by 2025 in the country at $8.2 \varnothing / \mathrm{kWh}$ (Fraunhofer ISE, 2012); the realized price in October 2019 was $\not 4.9 / \mathrm{kWh}$ (PV Magazine, 2019b). The UK's Department of Energy and Climate Change (DECC, 2011) projected in 2011 the lowest projected costs in its range would be $16.5 \mathrm{p} / \mathrm{kWh}$ and $13.6 \mathrm{p} / \mathrm{kWh}$ in 2015 and 2020 respectively; the last UK auction, in 2015 , tendered new capacity for $7.9 \mathrm{p} / \mathrm{kWh}$. More recently, the International Energy Agency's (IEA, 2015) projection, of the global average life cycle cost for solar PV in 2020, was $12 \mathrm{USc} / \mathrm{kWh}$; however, by 2018 the cost was already half of the IEA's projection. Models predicated on projections about technology costs over the century have become outdated within five years.

Figure 3(b) adds two other important points. First, these costs are comparable to those from fossil fuels, and indeed are rapidly becoming cheaper in a growing number of regions. For the two EU countries, this reflects in part the rising carbon price paid by coal, but in sunny countries with large PV deployment, PV is already cheaper than coal even without any carbon price. Indeed competitive tenders during 2019 broke three consecutive tariff records, with prices struck in the US (Los Angeles @ , 2c/kWh), Brazil (1.75c/kWh) and Portugal (1.6c/kWh) (PV Magazine, 2019a \& 2019c). These prices are well below the cost of fossil fuel generation even from existing coal plants, let alone the cost of building new ones.

If this reflected a wholly unpredictable and one-off technology break-through, one might still question its relevance to the fundamental assumptions of temporal independence. It was neither. The dominant technology is not some radical breakthrough, but the same basic technology of crystalline cells. The cost reductions have arisen mainly from incremental learning and development of the industry and its supply chains at scale. This is also suggested by the large cost variations between countries, which reflects not just the solar resource, but the maturity and scale of the local PV businesses. The point of Figure 3(b) is not that $\mathrm{PV}$ is competitive in some countries, but that we are in the midst of a dynamic process in which the global average cost will continue to decline as PV businesses expand globally.

Nor is this unique. For light duty transport, electric vehicles are cheaper to run than gasoline, and given battery costs have fallen even faster than PV, they are projected to be cheaper to buy as well within a few years as the market grows (Bloomberg NEF, 2019). ${ }^{5}$ Even for offshore wind, which was long assumed to be an exceptionally challenging and expensive technology, recent auctions in Europe have seen contract prices fall to a third of the cost only five years previously, to around the current wholesale price of electricity, associated with scale up from $8 \mathrm{GW}$ in 2014 to $23.1 \mathrm{GW}$ of installed offshore wind power capacity in 2018 (Gwec, 2019).

Only a decade ago, decarbonizing the electricity and transport sectors - which comprise over half of global $\mathrm{CO}_{2}$ emissions - was projected to be difficult and expensive. In fact, a range of zero carbon technologies are already cheaper in many countries than the assumptions that have been embodied in most projections in many cases, for decades to come - and the costs continue to decline with deployment.

\section{Implications for modeling.}

Optimizing equilibrium models ultimately use some form of projected abatement cost curve (Eq.1). Many use far more detailed abatement cost structures than DICE; by projecting costs for different specific technologies and sectors they build 'marginal abatement cost curves' (MACC) from the bottom-up. Figure 3 (inset) shows how the DICE projected cost curve for 2030 has varied over successive model vintages. With the same scale, this is inset with the high-profile (and hotly debated) engineering-based cost curve, produced by McKinsey in 2009, which projected abatement costs for 2030 associated with specific technology options. The most relevant central parts of the cost curve are, in technology terms, dominated

\footnotetext{
5 "Battery prices keep falling. As a result, we expect price parity between EVs and internal combustion vehicles (ICE) by the mid-2020s in most segments, though there is wide variation between geographies and vehicle segments"
} 
by low carbon electricity generation options. Notwithstanding numerous debates about this curve, we can draw three major conclusions:

- The cost curves in DICE for 2030 have varied substantially between successive model vintages -within a decade of the 1999 projections, the projected cost of cutting emissions by $10 \mathrm{GtC} 02$ fell by two-thirds, before rising somewhat in the most recent (2016) version of DICE, with a more non-linear cost function;

- Many of the sector options in corresponding parts of the McKinsey curve are ones in which the costs have fallen dramatically over the past few years - less than half way through the period of these projections, both the detailed engineering and the stylized DICE - had been rendered clearly wrong by innovation which has revolutionized the cost of decarbonizing electricity and transport in particular

- Comparing the two is complex, but however one places the DICE curves they appear substantially more expensive than these particular engineering estimates

(a) DICE Marginal cost curves over successive

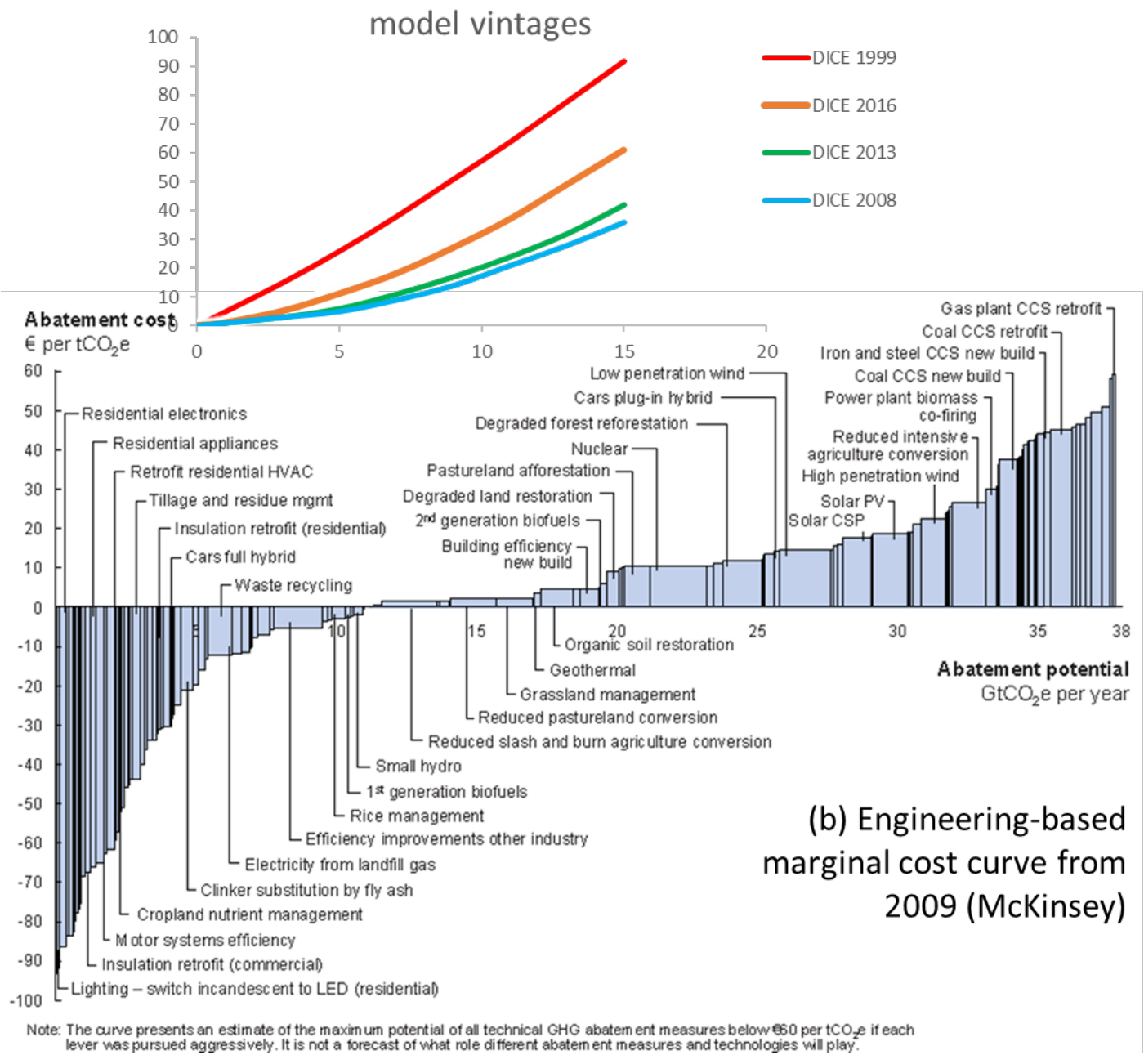

Figure 3 Marginal abatement cost curves

Note: The 'McKinsey curve' (McKinsey 2009) of abatement costs was criticized by many economists for finding a substantial portion of 'negative costs' (on the left hand side); this also complicates attempts to compare with 'topdown' curve curves like DICE (inset), which assume by construction that all cost-effective options are automatically 
adopted in the baseline, without need for climate action. The McKinsey curve also used a discount of 3.5\% which substantially lowers the cost of many capital-intensive options compared to market-based cost estimates. However, it clearly underestimated the potential for innovation and hence its values, like the DICE cost curves, have been similarly eclipsed by actual technology cost-reductions.

We thank Pu Yang, UCL for producing the DICE Marginal cost curves from successive version of DICE.

For the simple cost functions (eq. 1,2) this could simply be taken as evidence that $\mathrm{C}_{\mathrm{A}}$ has been revealed as much lower than assumed (or possibly the curve is far more non-linear). Indeed, the evidence of Figure 2 and the other data noted is that $\mathrm{c}_{\mathrm{A}}(\mathrm{t}) . \mu(\mathrm{t})^{{ }^{\mathrm{A}}}$ is close to zero for the first portions of the cost curve - or even negative for low $\mu$, which is the implication if zero carbon sources become cheaper than fossil fuels. For engineering models, the basic data similarly needs to be fundamentally rewritten. Though the transparency of assumptions in relation to ongoing cost data is often poor in many of the complex models examined in the IPCC Fourth and Fifth assessments, all of these have been rapidly outdated by reality.

However, as a perfunctory response, this is scarcely satisfactory. One can retort that innovation, by its nature, is impossible to predict. But this is only partially true, and it is certainly an inadequate response - to invest so much effort into models, and then say that innovation may make all the results irrelevant, is hardly satisfactory. What is the usefulness of models rooted in technology cost projections over this century if these can change so radically within a few years?

Clearly dynamic realism is crucial in terms of innovation, as well as inertia. We need to learn not just that our cost assumptions were radically wrong, but why. Because the timescales of climate change projections are long, and the models often inscrutable to outsiders, it has taken many years for the technology cost projections in past IAMs to be confronted by actual data, but the gap between prior assumptions and reality now cannot be ignored. An absolute priority must be to do better.

The huge decline in low carbon technology costs over the past decade, compared to most projections, could be taken to imply simply that the $\mathrm{c}_{\mathrm{A}}$ in Eqs 1 and 2 was vastly exaggerated. However, coupled with unambiguous evidence of the role of deployment in driving this, it obviously also implies that the future cost of abatement depends on cumulative action. The implication is not so much that $\mathrm{c}_{\mathrm{A}}$ in Eqs. 1 and 2 has been vastly exaggerated, but that the structural form is wrong.

Indeed, the initial policy-driven strategic deployment of the technologies noted above was expensive: the German Energiewende which substantially drove the PV revolution has cost over a hundred billion dollars. But this is not an ongoing global cost; it was transitional investment which has changed the landscape, globally, for the rest of the century. It has not simply prematurely attacked a high-cost element of the abatement cost curve, but fundamentally changed the curve itself. On a much lesser scale, many countries have yet to make the investments required to bring down the local costs of PV or electric vehicles (including charging infrastructure) at scale. Transitional investments, associated with globalizing PV and EV deployment, are still required.

Consequently, the evidence is the cost function is really something more like (Eq. 3) - that many of the costs assumed have simply reflected the need to invest at scale in order to secure and globalize cost reductions. Thus, that the costs assumed in the simplistic Eqs. 1 and 2, were in fact to an important degree misallocated - associated instead with the high initial cost of deploying low carbon technologies at scale. They were investments in transition, not an enduring cost. The investment in physical and business infrastructures still required in many countries to supply these technologies at scale will similarly be transitional investments. Such costs could be better expressed through transitional cost terms, such as $\mathrm{c}_{\mathrm{B}}$ in Eq.3.

In a neatly simplified way this would then properly express a second, fundamental form of dynamic realism: that the cost of a technology in one period would depend on how much effort been made in earlier periods, 
thereby securing valuable industrial learning and cost reductions for the rest of the century. Again, temporal independence has become an indefensible assumption, and must be replaced by something at least one step closer to dynamic realism.

\section{Path Dependence}

At any given point in time, the state of an economy reflects its previous evolution. An economy inherits, and bequests, a given set of infrastructure, technologies, industries, institutions and social norms. Such path dependence, the third element of temporal reality, is in the context of climate change closely related to concerns about 'carbon lock-in' (Unruh, 2002), the interlocking systems and political interests in the fossil fuel economy which make it hard to change. Conversely, transition to more efficient and low carbon systems may generate their own paths. Assumptions of temporal independence in models, by definition, are inconsistent with path dependence.

Path dependence obviously has a close relationship to both induced innovation and inertia. Inertia expresses a transitional cost of moving away from a given default path. Innovation, through economies of scale and learning-by-doing, tend to make an established path more attractive. These however are only some of the components. A recent overview (Aghion, Hepburn, Teytelboym, \& Zenghelis, 2019) identify at least five determinants of path dependence:

- Knowledge spillovers - a documented tendency for innovations to build upon prior, related innovations in cumulative ways

- Network effects - when the attractiveness of a technology depends upon interrelated networks of other users or suppliers

- Switching costs - the cost of switching to a different path e.g. due to the need for different infrastructure and to overcome incumbent interests

- Positive feedbacks - when technologies benefit from scale

- Complementarities - when technologies have complementary roles, such as renewables and storage

Path dependence thus embodies both inertia and induced innovation, but is more - it implies that past choices create a new default (or in economics, 'equilibrium' or 'business as usual' trajectory), and that there may be many such possible paths. It a distinct concept, with a rich history in economics. It is central to the theories and mathematics of evolutionary economics since (Arthur, 1989). It features strongly in the more mainstream economics literatures on 'sunspot equilibria' (eg. Azariadis \& Guesnerie, 1986; Farmer, 1993; Benhabib \& Farmer, 1999), which identify the potential for multiple different equilibrium paths shaped partly by expectations and the intervention of random events. It is neither a surprising nor new concept in economics, and perhaps particularly relevant for complex, capital-intensive sectors like energy, transport and urban infrastructure.

It is however absent from the structures of DICE and most other IAMs, which are ultimately rooted in the assumption that there is one unique, least-cost pathway for the global energy system, that can serve as a reference. Both the theories noted and the empirical evidence suggests this to be unrealistic. Despite the globalization of energy technologies and knowledge, energy and emitting systems remain very divergent. Per-capita $\mathrm{CO} 2$ emissions in Europe and Japan, for example, have remained at less than half the levels in North America for decades, in ways that reflect more than just the geography but also infrastructure, technology systems and policy choices, and show no sign of converging.

Long debates in the IPCC Special Report on Emission Scenarios finally agreed that we cannot plausibly reduce the future to just one projected, least-cost path plus abatement: analysis needs to consider multiple different kinds of futures as reference paths. Including and perhaps most obviously now, the scope for emerging economies to orient along completely different paths, perhaps radically different ones, based on the newfound cost-effectiveness of renewables and smart energy, transport and building energy systems. That is not, however, how DICE or most other IAMs have been understood or applied. Hence from this 
view, the assumption of temporal independence in DICE and many other IAMs, reflected in the simple equations (eq.1,2), are again invalidated.

Compared to the simplicity of these models, induced innovation and path dependence seemingly open up a host of unmanageable complexity, but again some improvement is offered by the simple addition of a transitional cost term (eq. 3). The degree of path dependence can be expressed in terms of the ratio of rigid $\left(c_{A}\right)$ to transitional $\left(c_{B}\right)$ costs. A system in which the first term (rigid costs) are very low, relative to transitional costs, has a high path dependence - change may take effort (transitional costs), but once on a different course, one tends to stick on it. The extreme of $c_{A}=0$ represents complete path dependence, as induced innovation and all the other interdependences noted mean that there is no incentive to return to what has become, in the truest meaning of the word, 'counterfactual'.

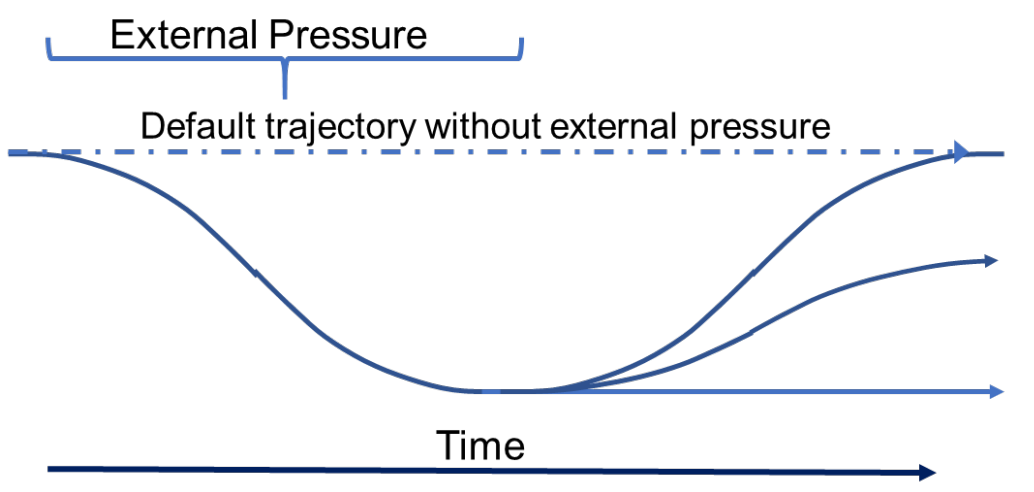

No path dependency (non-pliable)

Semi path dependent

Fully path dependent (pliable)

Note: The slope (speed of response) reflects the inertia of the system, represented by characteristic transition time $t$ (eq.5)

\section{Figure 4: Path dependency - illustration}

This is illustrated in Figure 5, showing the impact of a period of forcing a system away from its default trajectory. A fully path-dependent system will resist change, but when the forcing ceases, will remain on the new trajectory. As defined more fully in section 7, we term this pliable. In contrast, a non-pliable system is always attracted back to its initial trajectory; when the forcing is removed, it bounces back to the default path. In our case, the "forcing" would be abatement expenditure, and the "response", a change in abatement with respect to some reference trajectory.

\section{Why? Complexity and theoretical foundations}

Climate change is a very long term problem, and DICE and other IAMs are consequently very long term models. The most recent DICE-2016 model in its standard base assumptions results in an optimal scenario of global temperature rising to 4 degrees, before declining emissions - which occurs due to the combining of rising climate impacts, exogenously declining abatement costs, and exogenously assumed constraints on fossil fuels - feeds through to curtail global temperatures. Essentially however, aside from the climate damage assumptions, everything is determined by energy technology costs as projected by the modeler not just decades ahead, but over centuries.

An obvious question is why have DICE and many other IAMs embodied the demonstrably incorrect assumption of temporal independence? There are many potential answers, and in moving towards conclusions this article considers two: theory, and tractability.

DICE and related models are characterized as General Equilibrium models, a name that reflects origins in the basic theories of that name taught as fundamental in economics classes. Fundamentally, the theory is about balancing aggregate supply and demand in economies through markets and pricing, abstracted of time considerations. In the IAM world at least, this literal basis has however been interpreted as implying also equilibrium path solutions over time. 
The common sense interpretation of 'general' equilibrium, taken as implying a unique, stable least-cost pathway over time, is however not remotely implied by the formal axioms of GE theory. Arrow and Hahn's (1971) foundational book on General Competitive Analysis was shortly followed by the results of (Sonnenschein, 1973), (Mantel, 1974) and (Debreu, 1974), showing that GE theory is in fact incredibly unrestrictive. It does not imply that any given 'general' economic equilibrium is a unique one. It does not say anything about intertemporal trends. It does not imply monotonically increasing supply functions or rule out increasing returns to scale. Fundamental GE theory does not rule out multiple equilibria and absolutely does not imply that any given trajectory arising from smooth operation of market forces results in a least-cost global optimum.

The word 'general' in GE theory simply means balancing supply and demand across the economy. Fundamental GE theory has remarkably little predictive or constraining power: hence the title of a chapter on the topic: "Anything Goes: the Sonnenschein-Mantel-Debreu Theorem" (Mas-Colell, A., M. Whinston, 1995). Forty years on, and with some exceptions (notably (Brown \& Matzkin, 1996)) which impose modest constraints given certain microeconomic assumptions (as reviewed in (Rizvi, 2006)), the SMD critique still stands. The critique is not that GE theory is wrong, but on contrary, that it allows almost anything, and certainly in no way does it preclude any of the three components of dynamic realism articulated in this paper.

Thus, DICE and other general equilibrium models as implemented and understood by the climate change community represent only a tiny subset of the possible forms compatible with the fundamentals of GE theory.

\section{Complexity}

Another reason why so much of the optimizing IAM community follows DICE-like approaches, apart from habit, is probably because of its tractability. Relatively speaking, the models are easy to compute and wellbehaved, generating a global least-cost optimal pathway for any given set of assumptions.

This contrasts with the various efforts to include induced innovation in models, from a plethora of research efforts. A wide variety of endogenous growth models have been developed, as reviewed by (Gillingham, Newell, \& Pizer, 2008b) and (Koehler, Grubb, Popp, \& Edenhofer, 2006), but parameters are often hard to estimate. The best-known theoretical advance since then (Acemoglu, Aghion, Bursztyn, \& Hemous, 2012) underlined that innovation could radically reduce the cost of tackling climate change, but cast this in terms of specific subsidies to innovation, within a model that was criticized for its parameter assumptions and lack of path-dependence, being still rooted in an 'incorporeal' world of sequential general equilibria (Pottier, Hourcade, \& Espagne, 2014).

In common with evolutionary and more engineering-based models incorporating learning-by-doing and inertia, therefore, these models tend to generate more complex behavior, with multiple potential solutions; and sometimes counter-intuitive results (as with the Vogt-Schilb results on implications of inertia). The results can seem potentially quite indeterminate. This is less satisfactory to modelers, harder to communicate, and harder to implement computationally, which strongly deters such efforts particularly in more applied studies. ${ }^{6}$

Indeed, in researching this paper, the authors came across references to such features as "problems" which needed to be "solved". These are not problems to be "solved" by excluding dynamic realism and thus forcing such models to be more conventional - that is not a scientific approach. Like the macro 'sunspot'

\footnotetext{
${ }^{6}$ A clear example comes from the lead author's own Institute, which runs the global technology-rich TIAM model. One paper (Anandarajah, McDowall, \& Ekins, 2013) explored the impact of including learning-bydoing in this model (TIAM-Energy Technology Learning). However, it was so computationally complex to run, and uncertain to parameterize, that the TIAM-ETL has never been used again.
} 
models, in which expectations shape the outcomes, the fact that such models can generate a variety of behaviors, with results sensitive to assumptions, is telling us something important.

\section{An illustration: DICE with Pliable Abatement Cost Elements (DICE-PACE)}

Complexity is a problem if it obscures understanding and essential features. However, throwing away the essence - such as the exogenous technology and other assumptions of temporal independence in DICE and numerous other IAMs - clearly is unrealistic. The steps in this article do however point to a disarmingly simple way to explore some of the implications of greater dynamic realism.

Consequently, this section offers a highly reduced-form approach to strip away the complexities and suggest some fundamentals of the answer. The basic approach has already been built up, simply through the addition of a dynamic term into the DICE abatement cost function - a term dependent on the rate of change of abatement (the $\mathrm{c}_{\mathrm{B}}$ term in Eq.3). In economic language, then:

- the first $\mathrm{c}_{\mathrm{A}}$ term reflects the extent to which the system performs in the traditional way, with a cost fixed externally, rigidly related to a given distance from a reference trajectory;

- $\quad \mathrm{c}_{\mathrm{B}}$ expresses the transitional costs of accelerating abatement - which can include learning \& scalingup investments and long-lived infrastructure, as well as retirement cost of existing fossil-fuel assets - that do not persist after the adjustment is made;

- The relative scale of $\mathrm{c}_{\mathrm{A}}$ and $\mathrm{c}_{\mathrm{B}}$ expresses the extent to which the system is dominated by these static vs dynamic considerations, and hence the degree of overall path-dependence.

Thus induced innovation implies a lower $\mathrm{c}_{\mathrm{A}}$ to the extent that accumulated codified and tacit knowledge, scale economies, infrastructure and other factors can reduce the subsequent costs of abatement. A higher $\mathrm{c}_{\mathrm{B}}$ reflects dynamic investment in transition and adjustment costs of accelerating abatement. The ratio $\mathrm{c}_{\mathrm{B}} /$ $\mathrm{c}_{\mathrm{A}}$ can also then be taken as expressing the degree of path dependence; with full path dependence $\left(\mathrm{c}_{\mathrm{B}} / \mathrm{c}_{\mathrm{A}}\right.$ $=>\infty$ ), the system simply adapts to the current level and pathway, as redefining a dynamically altered reference trajectory.

In (Grubb, Mercure, Salas, Lange, and Sognaes 2018) we develop some underlying theory for the transitional cost component, demonstrating why it is non-linear and potentially close to quadratically increasing with the rate of abatement. For many purposes then we can approximate the exponents as similar $\left(\theta_{\mathrm{A}}=\theta_{\mathrm{B}}=\theta\right)$ in Eq.3, hence in more compact form and making the dependencies explicit:

$$
\text { Abatement cost as fraction of GDP), } \mathrm{C}_{\mathrm{AB}}(t, \mu, \dot{\mu})=\mathrm{c}_{\mathrm{A}}(\mathrm{t}) \cdot \mu(t)^{\theta}+\mathrm{c}_{\mathrm{B}}(\mathrm{t}) \cdot \dot{\mu}(t)^{\theta}
$$

In Grubb et al (2018) we then show that this can be expressed in terms in terms of the pliability of the system, reflecting the ratio of the two terms, together with a general characteristic timescale of system adjustment $\hat{t}$, which represents the time taken for a $50 \%$ emissions reduction in a pliable system to work through, at the same integrated cost as an equivalent non-pliable system. We can then express both elements of [5] in terms of the pliability $p$, where $\left(\mathrm{c}_{\mathrm{B}} / \mathrm{c}_{\mathrm{A}}\right)=p \cdot \frac{\hat{t}^{\theta}}{\theta+1} /(1-p)$, and characteristic timescale, in the form:

$$
C(t, \mu, \dot{\mu})=c_{A B}(t)\left[(1-p) \cdot \mu(t)^{\theta}+p \cdot \frac{\hat{t}^{\theta}}{\theta+1} \dot{\mu}(t)^{\theta}\right]
$$

In these equations we scale overall costs through $\mathrm{c}_{\mathrm{AB}}$ which can also change over time, to reflect a component of exogenous innovation which reduces both absolute and transitional costs. The pliability $p$ here formally expresses the relative importance of transitional costs (linked to the rate of change $\left.\dot{\mu}(t)^{\theta}\right)$, relative to rigid costs - costs defined exogenously in terms of the distance $\mu(t)$ from the reference trajectory. Pliability is defined in the range 0 to 1 : the closer to 1 , the more the dynamics of the system are characterized by the need for effort which changes the trajectory, but do not then incur an ongoing cost 
defined by the distance from the hypothetical baseline. $p=1$ captures the essence of a fully pliable - and hence, completely path-dependent - system.

We then insert this dynamic stylized representation of abatement costs into DICE, to obtain a variant we term DICE-PACE - DICE with Pliable Abatement Cost Elements. For this, we start with the open-access DICE2016R version, except that we use the carbon model parameters from the earlier version DICE2013R, ${ }^{7}$ which better represents decadal responses to emission reductions. ${ }^{8}$ We scale $c_{A B}$ in the same way as in DICE $^{9}$ with values from DICE2016R, as well as the cost exponent $\theta=2.6$. We take the standard form and parameters of the DICE damage function. We do not allow for negative emissions, in order to get a clearer picture of the energy transition itself: hence $0 \leq \mu \leq 1$. Finally, we assume that part (here: $60 \%$ ) of the non- $\mathrm{CO} 2$ radiative forcing (which is treated as exogenous in DICE) can also be abated, since it is unlikely that a society that makes great efforts to cut $\mathrm{CO}_{2}$ does not curb the emission of other greenhouse gases. ${ }^{10}$

To verify our results, our analysis with the MATLAB version of DICE was complemented by inserting the cost function into the GAMS version (by Pu Yang at UCL); results agreed to within 1\%. As in DICE, an optimization routine is used to find the optimal policy (abatement fraction and economic investment rate) over time. The modeling time is 300 years, sufficient to ensure that no end-of-simulation artefacts affect the results. We run the analysis for 3 values of the pliability: $p=0.0, p=0.5$, and $p=1.0$; and two values of the characteristic transition time, $\hat{t}=40$ years, and 20 years (noting that as defined in Grubb et al 2018, this represents roughly the time taken for a 50\% emissions reduction to work through the system).

Figure 5 Impact of system pliability and adjustment timescales on global abatement expenditure, emissions and temperature change

\footnotetext{
${ }^{7}$ To be precise, we use the equilibrium carbon reservoir sizes mateq $=588 \mathrm{GtC}$, mueq $=1350 \mathrm{GtC}$, mateq $=$ $10000 \mathrm{GtC}$, and the transition parameters phi $12=0.088$, phi23 $=0.0025$, in the notation of the GAMS code. Since the initial conditions for DICE2013R are set to 2010, as opposed to 2015 in DICE2016R, we obtain our initial condition by integrating the DICE2013 carbon model forwards in time for 5 years with an annual emission of $9.7 \mathrm{GtC}$. This yields mat $0=864 \mathrm{GtC}, \mathrm{mu} 0=1541 \mathrm{GtC}, \mathrm{ml} 0=10010 \mathrm{GtC}$ for the atmospheric, upper ocean, and lower ocean reservoir, respectively.

${ }^{8}$ The changes in DICE2016 are summarized in (Nordhaus, 2017).

${ }^{9}$ i.e. $c_{A}=C_{0}(t) \sigma(t)$ in [eq. 2/note 4], with exogenous decline in $C_{0}(t)$ and $\sigma(t)$.

${ }^{10}$ For simplicity we assume that this non- $\mathrm{CO} 2$ abatement scales with the $\mathrm{CO} 2$ abatement $\mu$ : $\mathrm{F}_{\text {nonCO2 }}(\mathrm{t})=\mathrm{F}_{\text {nonCO2,DICE }}(\mathrm{t}) *(1-0.6(\mathrm{t}))$, where $\mathrm{F}_{\text {nonCO2,DICE }}(\mathrm{t})$, where $\mathrm{F}_{\text {nonCO2, }}$ DICE $(\mathrm{t})$ is the non-CO2 forcing used in DICE. For simplicity, we do not explicitly apportion additional cost to this non-CO2 abatement, a simplifying assumption which partly offsets the apparently excessive abatement cost in DICE2016 (see Figure 3 and discussion).
} 
(a) System behavior with characteristic timescale $\mathrm{t}=40$ years
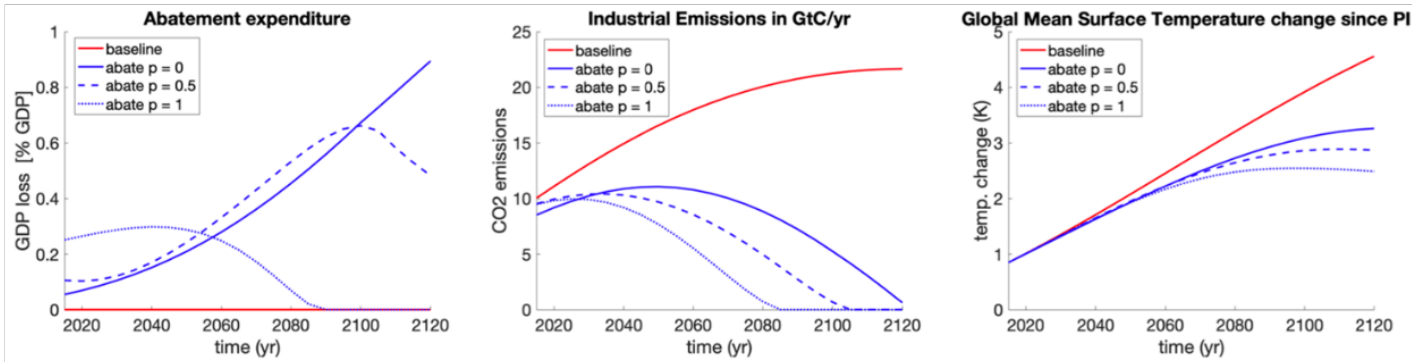

(b) System behavior with characteristic timescale $t=20$ years
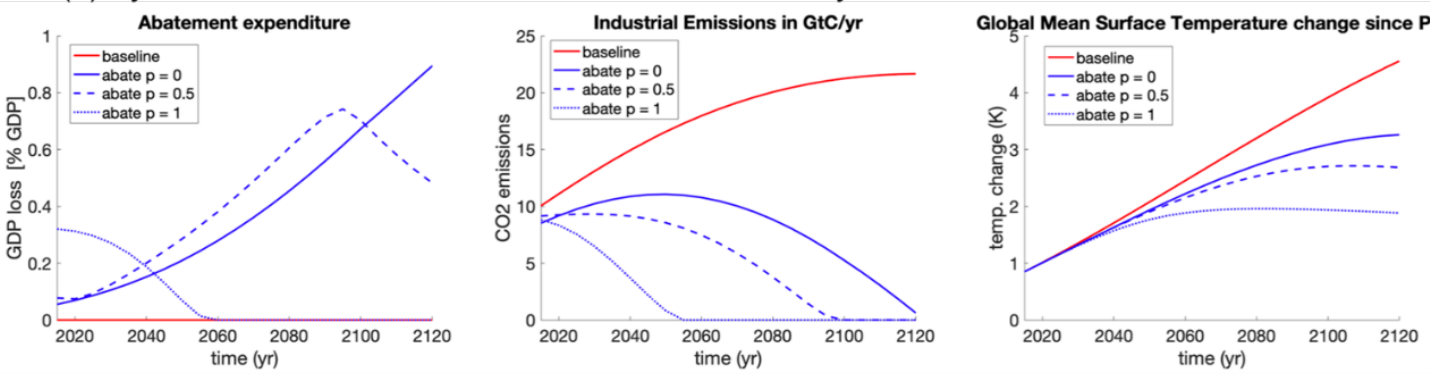

FIGURE CAPTION: Simulation results with the DICE-PACE (i.e. DICE with Pliable Abatement Cost Elements) model. In all plots, solid lines correspond to the case $p=0.0$ (i.e. standard DICE), dashed lines to $p=0.5$, and dotted lines to $p=1.0$, while a solid red line represents the no-policy case $(\mu=0)$. The top (bottom) row shows results for a transition time of 40 (20) years. In both rows, the left plots depicts abatement expenditure as percentage of GDP; the middle plot shows industrial CO2 emissions in $G t(C) / y e a r$, and the right plot the increase of global mean surface temperature w.r.t. pre-industrial levels.

Figure 5 shows that full abatement to 'net zero' emissions $(\mu=1)$ eventually occurs in each case, but much earlier - by 35 years (for $\hat{t}=20 \mathrm{yr}$ ) or 70 years (for $\hat{t}=40 \mathrm{yr}$ ) - for a pliable ( $=$ fully path-dependent) $p=1$ than for $p=0$. With $p=0$ (the standard case, with no inertia) the system can jump from zero abatement before the onset of the simulation to $15 \%$, because there are no transition costs. But in later decades, large costs persist and grow, as $\mu$ increases (once $\mu=1$, the slow exogenous decrease of $\mathrm{C}_{0}$ in DICE dominates (after 2125; not plotted).

With some pliability, paying initially to increase $\dot{\mu}$ (speed up the transition) thus reduces the absolute costs in the future. $p>0$ logically leads to lower carbon concentrations, lower temperatures, and lower climateinflicted damage.

At first glance, $p=1$ - with its implication that the rigid cost term in eq.3, $\mathrm{C}_{\mathrm{A}}=0$ - may seem entirely implausible. One could simply treat our study as showing that dynamic realism could matter and is worthy of study. However, the revolution in renewable electricity sources suggests in fact that electricity production has a high degree of pliability: huge investments have been required, but innovation through learning has already reduced the long-run cost of decarbonization, and the global costs will decline further as more countries extend their domestic capacity. There may be continuing 'adjustment' costs: as renewable industries build up in different regions and existing fossil fuel capacity is retired; and as electric charging infrastructure is rolled out and refineries and gasoline stations become redundant. But it is now far from certain that a low carbon electricity system will ultimately be any more expensive than a high-carbon one.

If renewables-based systems are now as cheap as fossil fuels, $p$ was apparently close to 1 all along, at least for electricity-related options. Many of the costs apportioned to $c_{\mathrm{A}}$, as the only term in Eqs. 1 and 2, in fact have turned out to be transitional. Empirically, it is possible to argue that at least for some of the major sectors involved, $\mathrm{c}_{\mathrm{A}}$ is turning out to be small or even negative - renewables and electric cars may turn out to be cheaper than the old-fashioned technologies relying on extracting, processing and burning carbon, 
particularly when the multiple environmental impacts are factored in. This also has important knock-on effects for decarbonizing transport, heating and cooling, and many industrial uses. This does not mean the transition to date has been cheap, and obviously continuing efforts to expand renewables are needed, but the consequences - including potential multiple benefits - are enduring.

To the extent that energy-related systems in reality have considerable inertia, induced innovation, and path dependence, the results shown suggest at least three major implications. If indeed pliability is high and characteristic transition times are in the range we explored, then even with the other assumptions mostly mimicking DICE:

(a) Optimal emissions diverge from baseline sharply but steadily and, after a few years, proceed on an almost linear reduction to net zero within about 40-70 years, in contrast to the traditional DICE optimal result of global emissions readjusting in the first period, but then rising for a few decades before declining towards zero some time next century;

(b) the abatement effort / investment / cost is substantially greater for some decades - initially by a factor of around 5 for full pliability compared to the traditional case - but then declines; this is the opposite of the pattern in traditional treatments, in which the cost rises steadily as damage accumulates (at least until zero emissions are reached)

(c) Global temperature is stabilized at about 1 deg.C lower than in the traditional case (with $p=1$, warming stays below 2 degree ( 2.5 degree) for $\hat{t}=20 \mathrm{yr}(\hat{t}=40 \mathrm{yr})$ despite the moderate damage function $)$ - and the total discounted cost is 5 to 10 times lower than predicted in the classical case. ${ }^{11}$

In short, pliability $(p>0)$ logically leads to lower carbon concentrations and temperatures, and climateinflicted damage, because it pays to make greater effort up front which lowers subsequent abatement and transitional costs. Models which ignore the impact of inertia, induced innovation and path dependence erroneously suggest to postponing abatement, while greater dynamic realism implies it is optimal to make bigger efforts initially.

\section{Implications}

The absolute values of results of course depend on the numerical assumptions, but the structural conclusions do not: dynamic realism is absolutely crucial to establishing the form of optimal pathways, the level of effort justified, and the resulting long-term temperature and total costs imposed by climate change. A striking feature, indeed, is that whilst cost-benefit studies over the past two decades have typically led to temperatures far higher than the scientific precautionary approach - fueling a major divergence between scientists and many economic studies - the tension is far less if the emitting system is pliable. Far more modest assumptions about climate damages can, for example, still lead to temperatures within the precautionary range of the Paris Agreement being optimal, even without explicit risk considerations.

Various attempts could be made to try and defend the use of exogenous technology costs in IAMs. One is that the initial 'strategic deployment' of the technologies noted above was indeed expensive. This is true but misses the point: the many tens of billions of Euros spent in the German Energiewende is not an ongoing global cost, but a transitional investment which has changed the landscape, globally, for the rest of the century. It has not simply prematurely attacked a high-cost element of the abatement cost curve, but fundamentally changed the curve itself.

\footnotetext{
11 The total discounted abatement costs from 2015 to 2214 for $\hat{t}=20 \mathrm{yr}$ are $\$ 22.6$ trillion for $p=0, \$ 19.0$ trillion for $p=0.5$, and $\$ 2.41$ trillion for $p=1$, which suggests that disregarding the path dependence of abatement costs leads to a gross overestimation of the overall costs of decarbonisation. The overestimation of abatement cost may affect not only economic, but also political feasibility of abatement [https://onlinelibrary.wiley.com/doi/epdf/10.1002/wcc.621].
} 
More potentially relevant to the currently-dominant approach in IAMs, one could argue that innovationrelated policies - including strategic deployment - should be considered largely separate from the wider efforts on global emission reductions; and so to a first approximation future technology costs can still be treated as exogenous for global IAM modeling, as "somebody else's effort". This however poses a severe dilemma as a general defense of current practice and its common interpretation. A major conceptual claim associated with global IAMs is that they identify 'globally efficient abatement' - which is equated with working up the curve of 'marginal abatement cost', in ways indexed through a carbon price. Innumerable economists and major economic institutions have echoed this view. Only six years ago The Economist (2014) decried solar deployment as "by far the most expensive way of reducing carbon emissions", whilst a year earlier the OECD (2013) declared that "Other policies such as feed-in tariffs, industry regulation and subsidies, are far less economically preferable than carbon pricing to reduce emissions...". In reality, the targeted deployment of renewables through such means has helped to revolutionize the global landscape for low-cost global abatement.

If IAM modelers acknowledge the reality and potentially central importance of deployment-induced learning but declare it to be outside the scope of their models, they are in effect abandoning the claim that IAM models capture the most important elements of a least-cost approach. This would undermine the normal claim about the superior efficiency of global carbon pricing, and IAMs as the guide to least-cost scenarios. Such modeling reflects static, not dynamic, efficiency. If the message is changed in this way to admit that innovation maybe really important and that strategic deployment of emerging technologies may well be highly cost-effective ways of stimulating innovation, which would radically change our estimated MACC numbers - that is a very different and far more modest message. It undermines what can reasonably be claimed about such models' insights into either optimal policy, or projected costs.

The empirical evidence summarized in section 4 in fact points to an intrinsically more complex landscape, which needs to combine all such elements. It is clear that innovation as measured by patents, and private R\&D, does respond to general energy prices (e.g. the reviews by (Popp, D., 2002; Popp, 2019), and broad-based carbon pricing (e.g. (Aghion et al., 2016; Calel \& Dechezlepretre, 2016). Moreover patents are, of course, only part of the processes that bring down the costs of low carbon systems. The evidence in the first part of section 4 thus underlines that economy-wide abatement will, therefore, enhance low carbon innovation (and also help to avoid future lock-in) thereby supporting subsequent emission reductions. Economy-wide targets and incentives can also support major structural shifts. It follows that that indeed pliability $p>0$ across the whole economy, and models which assume otherwise underestimate the value of economy-wide abatement.

At the same time it is clear from the evidence summarized in the second part of section 4 that technology and sector-specific incentives and market-building programs like the Energiewende have driven more radical and game-changing innovation, such as now seen in renewables. The implicit climate value of specific PV investments was by implication very much higher than, say, coal to gas switching, as demonstrated mathematically by (Newbery, 2018).

The implication is that the landscape of emissions abatement cannot be summarized in terms of a simple, one-dimensional metric of a rigid marginal cost curve (cost per ton CO2). Many abatement actions have intrinsically dynamic components of transitional cost, associated with inertia and induced innovation in systems with significant path-dependence. The landscape is multidimensional. The components of abatement vary according to their wider learning potential and dynamic characteristics of the associated investments and sectors: mathematically, because both pliability $p$ and transition time $\hat{t}$ may vary hugely for different interventions.

Hence, the fact that we find optimal abatement expenditure in a fully pliable global system to be several times that of a non-pliable system is not saying that 'the global carbon price' should be higher by the same amount (which anyway would confuse marginal with total effort). It is pointing to the collective value of multiple interventions which could change the future of the global energy system. What this 
paper has demonstrated is that in addition to a general amplification of economy-wide efforts due to economy-wide processes of dynamic adjustments, numerous more targeted interventions may form part of an effective mitigation strategy, to drive long-term transformation of multiple economic sectors.

Such a perspective may be challenging to the IAM community, but would be preferable to the situation of projecting technology costs to the end of the century which turn out to be wholly redundant within a decade because the models ignore the real drivers of innovation. Surely the ambition should be to do better than that and consider at least some dimensions of dynamic efficiency within global IAMs. Particularly with the technology breakthroughs already secured, modeling should still at minimum recognize the reality of regional and global cost reductions associated with learning-by-doing and scale, as technologies move from national strategic deployment to accelerated global diffusion.

\section{Conclusions}

We have outlined three dynamic aspects of energy-industrial systems relevant to climate change mitigation, to highlight components which together could help to characterize dynamically realistic properties of low carbon energy transitions. We have shown that the widely-used DICE model, and many other Integrated Assessment Models, embody an assumption of temporal independence between successive time periods, which is inconsistent with these realities.

Inertia, the first component, reflects many factors which create resistance to rapid transformations away from default energy-emission trajectories. These include capital stock lifetimes and the significant timescales involved in the growth and diffusion of new technologies, as well as social, institutional, and political resistance to change. We point to evidence that the dominant phases of growth and decline of relevant technological systems have often taken 20-40 years.

Induced innovation, the second component, reflects the fact that innovation can be heavily influenced by market conditions and related policy, which changes the economic landscape and deployed scale of new technologies. IAMs with temporal independence require predictions of technology and other abatement costs decades ahead, but past projections have been shown to be wildly wrong within a few years. This has not been due simply to exogenous and unforeseeable surprises: a wide variety of evidence demonstrates that innovation and associated cost reductions flow significantly from investments in earlier periods, and hence should be endogenous to modeling.

Path dependence, the third and integrating dimension of dynamic reality, goes beyond these two factors, to include a variety of network effects of supply systems and infrastructure, positive feedbacks and complementarities with other technologies and systems. These can create self-reinforcing tendencies for a wide variety of different potential paths, which then become the default (as with a new equilibrium path).

These characteristics are all compatible with the fundamentals of General Equilibrium theory, and other long-standing debates in mainstream economics as well as evolutionary economics and the findings of science and technology studies. In contrast to the complexities of much evolutionary and endogenous change modeling, however, we show that some essential features of dynamic realism can be captured in highly stylized IAMs by adding a second component to the cost term, dependent upon the rate of change. Many of the costs that have traditionally been represented as a rigid cost function (exogenously defined) may in fact reflect transitional costs.

We transform the relevant cost functions in terms of the pliability of the system, reflecting the degree of path dependence, and the transitional timescale, a characteristic time required for the system to adjust, reflecting the inertial resistance to, and scale of investment required for, changing course. We insert this cost function into DICE - which we term DICE-PACE - to explore the significance of dynamic realities for model results. 
We find that results can indeed be very sensitive to these dynamic characteristics, in at least three ways. First, with a pliable system, the optimal emissions profile diverges from baseline sharply but steadily and, after a few years, proceeds on an almost linear reduction to net zero. This reflects an almost linear increase in abatement, in sharp contrast to the conventional result in which emission reductions are deferred until damages rise and abatement costs decline due to exogenous factors. Second, the initial abatement effort is much bigger - several times larger than in the conventional result, because early actions contribute to a future stream of emission reductions, and hence are much more valuable. Third, the 'optimal' global temperature is substantially lower. The scale of the changes in abatement rates and final temperature are sensitive not only to the degree of pliability, but also very strongly to the assumed characteristic timescale of system transition. Even with the 'standard' DICE damage function, widely criticized as underestimating the risks and costs of climate change, a scenario with full pliability and only 20 -year characteristic timescale results keeps temperatures substantially below 2 deg.C as the optimal result.

In conclusion, the assumption of temporal independence which characterizes DICE and many IAMs is empirically indefensible. We have shown that it is possible to include dynamic realism into IAMs in a stylized way without adding too much complexity. Ignoring the dynamic characteristics of abatement produces misleading insights for policy, potentially leading to a postponement of a transition that should be initiated early because it needs time and up-front investment. Far greater analytic and empirical attention should be given to ways of representing, and estimating, the dynamic realities of energyemission systems in integrated assessments. 


\section{References}

Acemoglu, D., Aghion, P., Bursztyn, L., \& Hemous, D. (2012). The environment and directed technical change. American Economic Review. Nordhaus and Boyer. https://doi.org/10.1257/aer.102.1.131

Aghion, P., Hepburn, C., Teytelboym, A., \& Zenghelis, D. (2019). Path dependence, innovation and the economics of climate change. In Handbook on Green Growth (pp. 67-83). https://doi.org/10.4337/9781788110686.00011

Aghion, P., Dechezleprêtre, A., Hémous, D., Martin, R., \& Van Reenen, J. (2016). Carbon Taxes, Path Dependency, and Directed Technical Change: Evidence from the Auto Industry. Journal of Political Economy, 124(1). https://doi.org/10.1086/684581

Anandarajah, G., McDowall, W., \& Ekins, P. (2013). Decarbonising road transport with hydrogen and electricity: Long term global technology learning scenarios. International Journal of Hydrogen Energy, 38(8), 3419-3432. https://doi.org/10.1016/J.IJHYDENE.2012.12.110

Arthur, W. B. (1989). Competing Technologies, Increasing Returns, and Lock-In by Historical Events. The Economic Journal, 99(394), 116. https://doi.org/10.2307/2234208

Azariadis, C., \& Guesnerie, R. (1986). Sunspots and Cycles. The Review of Economic Studies, 53(5), 725. https://doi.org/10.2307/2297716

Barbieri, N. (2016). Fuel prices and the invention crowding out effect: Releasing the automotive industry from its dependence on fossil fuel. Technological Forecasting and Social Change, 111, 222-234. https://doi.org/10.1016/j.techfore.2016.07.002

Benhabib, J., \& Farmer, R. E. A. (1999). Chapter 6 Indeterminacy and sunspots in macroeconomics. Handbook of Macroeconomics, 1, 387-448. https://doi.org/10.1016/S1574-0048(99)01009-5

Bento, N., \& Wilson, C. (2016). Measuring the duration of formative phases for energy technologies. Environmental Innovation and Societal Transitions. https://doi.org/10.1016/j.eist.2016.04.004

Bettencourt, L. M. A., Trancik, J. E., \& Kaur, J. (2013). Determinants of the Pace of Global Innovation in Energy Technologies. PLoS ONE, 8(10), e67864. https://doi.org/10.1371/journal.pone.0067864

Brown, D. J., \& Matzkin, R. L. (1996). Testable Restrictions on the Equilibrium Manifold. Econometrica. https://doi.org/10.2307/2171830

Calel, R., \& Dechezlepretre, A. (2016). Environmental policy and directed technological change: evidence from the European carbon market. The Review of Economics and Statistics, 98(1), 173 191. https://doi.org/10.1162/REST_a_00470

Debreu, G. (1974). Excess demand functions. Journal of Mathematical Economics. https://doi.org/10.1016/0304-4068(74)90032-9

Dietz, S., \& Venmans, F. (2019). Cumulative carbon emissions and economic policy: In search of general principles. Journal of Environmental Economics and Management, 96, 108-129. https://doi.org/10.1016/J.JEEM.2019.04.003

Farmer, J. D., \& Lafond, F. (2016). How predictable is technological progress? Research Policy. https://doi.org/10.1016/j.respol.2015.11.001

Farmer, R. E. A. (1993). The Macroeconomics of Self-Fulfilling Prophecies (First Edition ed.). MIT Press: Cambridge MA.

Gillingham, K., Newell, R. G., \& Pizer, W. A. (2008a). Modeling endogenous technological change for climate policy analysis. Energy Economics. https://doi.org/10.1016/j.eneco.2008.03.001

Gillingham, K., Newell, R. G., \& Pizer, W. A. (2008b). Modeling endogenous technological change for climate policy analysis. ENERGY ECONOMICS, 30(6), 2734-2753. 
https://doi.org/10.1016/j.eneco.2008.03.001

Goulder, L. H., \& Mathai, K. (2000). Optimal CO2 abatement in the presence of induced technological change. Journal of Environmental Economics and Management.

https://doi.org/10.1006/jeem.1999.1089

Grubb, Michael, Jean-Francois Mercure, P., \& Salas, Rutger-Jan Lange, I. S. (n.d.). Systems Innovation, Inertia and Pliability: A mathematical exploration with implications for climate change abatement. Cambridge. Retrieved from https://www.eprg.group.cam.ac.uk/wp-content/uploads/2018/03/1808Text.pdf

Grübler, A., Nakićenović, N., \& Victor, D. G. (1999). Dynamics of energy technologies and global change. Energy Policy. https://doi.org/10.1016/S0301-4215(98)00067-6

Ha-Duong, M., Grubb, M. J., \& Hourcade, J.-C. (1997). Influence of socioeconomic inertia and uncertainty on optimal CO2- emission abatement. Nature, 390(6657). https://doi.org/10.1038/36825

Hicks, J. (1932). A theory of wages. MacMillan.

Kavlak, G., McNerney, J., \& Trancik, J. E. (2016). Evaluating the Causes of Photovoltaics Cost Reduction. SSRN. https://doi.org/10.2139/ssrn.2891516

Kavlak, G., McNerney, J., \& Trancik, J. E. (2018). Evaluating the causes of cost reduction in photovoltaic modules. Energy Policy, 123, 700-710. https://doi.org/10.1016/J.ENPOL.2018.08.015

Koehler, J., Grubb, M., Popp, D., \& Edenhofer, O. (2006). The transition to endogenous technical change in climate-economy models: A technical overview to the Innovation Modeling Comparison Project. ENERGY JOURNAL, (1), 17-55.

Kumar, S., \& Managi, S. (2009). Energy price-induced and exogenous technological change: Assessing the economic and environmental outcomes. RESOURCE AND ENERGY ECONOMICS, 31(4), 334353. https://doi.org/10.1016/j.reseneeco.2009.05.001

Ley, M., Stucki, T., \& Woerter, M. (2016). The Impact of Energy Prices on Green Innovation. ENERGY JOURNAL, 37(1), 41-75. https://doi.org/10.5547/01956574.37.1.mley

Lichtenberg, F. R. (1986). Energy Prices and Induced Innovation. Research Policy, 15(2), 67-75. https://doi.org/10.1016/0048-7333(86)90002-8

Lin, B., \& Chen, Y. (2019). Does electricity price matter for innovation in renewable energy technologies in China? ENERGY ECONOMICS, 78, 259-266. https://doi.org/10.1016/j.eneco.2018.11.014

Mantel, R. R. (1974). On the characterization of aggregate excess demand. Journal of Economic Theory. https://doi.org/10.1016/0022-0531(74)90100-8

Mas-Colell, A., M. Whinston, and J. G. (1995). Microeconomic Theory.

Nemet, G. F. (2019a). How solar energy became cheap a model for low-carbon innovation. Routledge.

Nemet, G. F. (2019b). How solar energy became cheap a model for low-carbon innovation. Routledge. Retrieved from https://www.routledge.com/How-Solar-Energy-Became-Cheap-A-Model-for-LowCarbon-Innovation-1 st-Edition/Nemet/p/book/9780367136598

Newbery, D. (2018). Evaluating the case for supporting renewable electricity. Energy Policy, 120, 684696. https://doi.org/10.1016/j.enpol.2018.05.029

Newell, R. G., Jaffe, A. B., \& Stavins, R. N. (1999). The Induced Innovation Hypothesis and EnergySaving Technological Change. The Quarterly Journal of Economics, 3(August), 941-975. https://doi.org/10.1162/003355399556188

Noailly, J., \& Smeets, R. (2015). Directing technical change from fossil-fuel to renewable energy innovation: An application using firm-level patent data. Journal of Environmental Economics and 
Management, 72, 15-37. https://doi.org/10.1016/J.JEEM.2015.03.004

Nordhaus, W. D. (1969). An Economic Theory of Technological Change. American Economic Review, 59(3).

Nordhaus, W. D. (2002). Modeling induced innovation in climate change policy. In T. C. and the E. In: Grubler, A., Nakicenovic, N., Nordhaus, W. (Eds.) (Ed.), Technological Change and the Environment. Resources for the Future Press, Washington, DC.

Nordhaus, W. D. (2014). The perils of the learning model for modeling endogenous technological change. Energy Journal. https://doi.org/10.5547/01956574.35.1.1

Nordhaus, W. D. (2017). Revisiting the social cost of carbon. Proceedings of the National Academy of Sciences of the United States of America. https://doi.org/10.1073/pnas.1609244114

Nordhaus, W., \& Sztorc, P. (2013). DICE 2013R: Introduction and User's Manual. Retrieved from $\mathrm{http}: / / \mathrm{www}$. econ.yale.edu/ nordhaus/homepage/homepage/documents/DICE_Manual_100413r1.pdf

Pezzey, J. C. V. (2019). Why the social cost of carbon will always be disputed. Wiley Interdisciplinary Reviews: Climate Change, 10(1), e558. https://doi.org/10.1002/wcc.558

Popp, D. (2002). Induced Innovation and Energy Prices. American Economic Review, 92(1), 160-180. https://doi.org/10.1257/000282802760015658

Popp, D. (2002). Induced Innovation and Energy Prices. American Economic Review, 92(1), 160-180. Retrieved from http://pubs.aeaweb.org/doi/10.1257/000282802760015658

Popp, D. (2019). Environmental Policy and Innovation: A Decade of Research (No. 25631). Retrieved from http://www.nber.org/papers/w25631

Popp, D., Newell, R. G., \& Jaffe, A. B. (2010). Energy, the Environment, and Technological Change. Handbook of the Economics of Innovation, 2, 873-937. https://doi.org/10.1016/S01697218(10)02005-8

Pottier, A., Hourcade, J. C., \& Espagne, E. (2014). Modeling the redirection of technical change: The pitfalls of incorporeal visions of the economy. Energy Economics. https://doi.org/10.1016/j.eneco.2013.12.003

Rizvi, S. A. T. (2006). The Sonnenschein-Mantel-Debreu results after thirty years. History of Political Economy. https://doi.org/10.1215/00182702-2005-024

Romer, P. M. (1990). Endogenous Technical Change. Journal of Political Economy, 98(5).

Rubin, E. S., Azevedo, I. M. L., Jaramillo, P., \& Yeh, S. (2015). A review of learning rates for electricity supply technologies. ENERGY POLICY, 86, 198-218. https://doi.org/10.1016/j.enpol.2015.06.011

Samadi, S. (2018). The experience curve theory and its application in the field of electricity generation technologies - A literature review. Renewable and Sustainable Energy Reviews, 82, 2346-2364. https://doi.org/10.1016/J.RSER.2017.08.077

Schumpeter, J. (1934). The theory of economic development - An inquiry into profits, capital, credit, interest, and the business cycle. Regional Studies.

Sonnenschein, H. (1973). Do Walras' identity and continuity characterize the class of community excess demand functions? Journal of Economic Theory. https://doi.org/10.1016/0022-0531(73)90066-5

Unruh, G. C. (2002). Escaping carbon lock-in. Energy Policy, 30(4), 317-325. https://doi.org/10.1016/S0301-4215(01)00098-2

van der Ploeg, F., \& Rezai, A. (2019). Simple Rules for Climate Policy and Integrated Assessment. Environmental and Resource Economics, 72(1), 77-108. https://doi.org/10.1007/s10640-018-0280-6 
Vogt-Schilb, A., Meunier, G., \& Hallegatte, S. (2018). When starting with the most expensive option makes sense: Optimal timing, cost and sectoral allocation of abatement investment. Journal of Environmental Economics and Management, 88, 210-233.

https://doi.org/10.1016/J.JEEM.2017.12.001

\section{Renewable Energy Cost references for Figure 3:}

BEIS (2016), Electricity generation costs, Available at:

https://assets.publishing.service.gov.uk/government/uploads/system/uploads/attachment_data/file/566567/BEIS_Ele ctricity_Generation_Cost_Report.pdf Accessed: $14^{\text {th }}$ November 2019

BEIS (2019), CfD Allocation Round 3 auction results

https://www.gov.uk/government/publications/contracts-for-difference-cfd-allocation-round-3-results/contracts-for-

difference-cfd-allocation-round-3-results

Bloomberg/CFLI (2019), Financing the Low-Carbon Future A Private-Sector View on Mobilizing

Climate Finance, Climate Finance Leadership Initiative,

https://data.bloomberglp.com/company/sites/55/2019/09/Financing-the-Low-Carbon-Future CFLI-Full-

Report_September-2019.pdf Accessed: 25 ${ }^{\text {th }}$ November 2019

DECC (2011), Review of the generation costs and deployment potential of renewable electricity technologies in the UK, Available at:

https://assets.publishing.service.gov.uk/government/uploads/system/uploads/attachment_data/file/147863/3237cons-ro-banding-arup-report.pdf Accessed: $14^{\text {th }}$ November 2019

Fraunhofer ISE (2012), Levelized cost of electricity renewable energies, Available at:

https://www.ise.fraunhofer.de/content/dam/ise/en/documents/publications/studies/EN2012_ISE_Studie_Stromgesteh ungskosten_Erneuerbare\%20Energien eng-version 17-01-2013 final.pdf Accessed: $11^{\text {th }}$ November 2019

Global Wind Energy Council (GWEC) (2019), Global wind report 2018, Available at: https://gwec.net/wpcontent/uploads/2019/04/GWEC-Global-Wind-Report-2018.pdf Accessed: 24 ${ }^{\text {th }}$ November 2019

IEA (2010), Projected costs of generating electricity, 2010 Edition, Available at: https://www.oecdnea.org/ndd/pubs/2010/6819-projected-costs.pdf Accessed: 12 ${ }^{\text {th }}$ November 2019

IEA (2015), Projected costs of generating electricity, 2015 Edition, Available at: https://www.oecdnea.org/ndd/pubs/2010/6819-projected-costs.pdf Accessed: $12^{\text {th }}$ November 2019

IRENA (2019), Renewable energy auctions: Status and trends beyond price, Available at: https://www.irena.org//media/Files/IRENA/Agency/Publication/2019/Jun/IRENA_Auctions beyond price 2019 findings.pdf Accessed: $16^{\text {th }}$ November 2019

PV Magazine (2019a), Brazil A-4 auction signs $211 \mathrm{MW}$ of solar for record-low price of $\$ 0.0175 \mathrm{kWh}$, Available at: https://www.pv-magazine.com/2019/07/01/brazil-a-4-auction-signs-211-mw-of-solar-for-record-lowprice-of-0-0175-kwh/ Accessed: $16^{\text {th }}$ November 2019

PV Magazine (2019b), German PV tender brings average solar price of $€ 0.049 / \mathrm{kWh}$, Available at: https://www.pv-magazine.com/2019/10/21/german-pv-tender-brings-average-solar-price-of-e0-049-kwh/, Accessed: $16^{\text {th }}$ November 2019

PV Magazine (2019c), Portuguese auction attracts world record bid of $€ 14.8 / \mathrm{MWh}$ for solar, Available at: https://www.pv-magazine.com/2019/07/31/portuguese-auction-attracts-world-record-bid-of-e14-8-mwh-for-

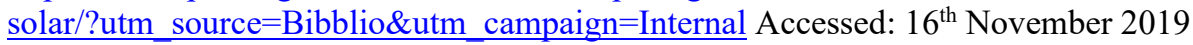

